\title{
THE DESIGN OF A SMALL-SCALE PLASTIC EXTRUDER MACHINE
}

\author{
Attila GYÁRFÁs, ${ }^{1}$ Attila GERGELY ${ }^{2}$ \\ Sapientia Hungarian University of Transylvania, Faculty of Technical and Human Sciences Târgu Mureș, \\ Department of Mechanical Engineering, Târgu Mureș, Romania \\ ${ }^{1}$ gyarfasattila31@gmail.com \\ 2 agergely@ms.sapientia.ro
}

\begin{abstract}
This paper discusses the design steps, working principle and structure of a small-scale thermo-plastic extrusion machine that will be used in a laboratory at the Sapientia University. The aim of the laboratory is to present the polymer processing technologies by student-built machines and to stress the importance of plastic recycling. In order to recycle plastic parts a grinding process is necessary, followed by extrusion. During the process the machine melts the polymer and extrudes a filament that can be converted into granulates or used as it is. The structure of the extrusion machine is rather similar to that of a commercial one, however it focuses on presenting the manufacturing principles and cost effectiveness.
\end{abstract}

Keywords: thermoplastics, polymer, extrusion, design, 3D modeling.

\section{Introduction}

Extrusion as a polymer processing technology appeared at the beginning of the XIX. century. Mc Phearson invented the screw press in 1818, that improved substantially with the development of the rubber industry. Thomas Hancock, in 1820, invented a machine that used gears to recycle rubber goods. The machine was optimized by Edwin Caffe. In 1833 Charles Good-year invented the vulcanization process of rubber. [1, 2] In 1879 Matthew Gray invented the screw extruder that revolutionized the polymer industry. [2] Roberto Colombo developed the twin screw extruder. [3]

Polymer extrusion can be compared to the process of fabricating metal rods. Metal rods are manufactured at high temperatures and it is a discontinuous process, whereas polymeric materials are extruded at lower temperatures with a continuous process. The extrusion process is the most widely used polymer processing technology that involves melting, homogenization and pressurization of the polymer melt, which is then forced out in a predefined cavity resulting in the formation of the final products shape. In order to preserve the dimension of the extruded polymeric product a specialized cooling apparatus cools down the product and if necessary calibrates a dimension. Examples of extruded products from polymeric materials include pipes, sheets, electrical wire insulation, PVC window profiles. The raw material is called a granulate which is produced of thermoplastic polymeric material, however it can be a shredded product in the case of recycling applications. 85-90 \% of polymer products made from thermoplastic materials, due to their good processability and mechanical properties are HDPE, LDPE, PET, PVC, PP, PS [2].

The most widely used extrusion machines are the single and the twin screw extruders. These machines have the following main components: electric motors, drivetrain, bearing, feeding system, screw, heating and cooling system, barrel, die and temperature and pressure sensors.

The drivetrain of the machine consists of the electric motor, a reducer and the bearing, whereas the feeding system is made up of the hopper in our case and a small opening on the barrel. The polymer turns to a melted state due the heating system and the friction generated in the barrel. There is a pressure sensor at the end of the barred 
in front of the die to provide an input for a feedback mechanism that regulates the heating and of the speed of the screw. The molten plastic is then formed to the desired shape by the die. The screws are standardized by the diameter/length ratio $(\mathrm{D} / \mathrm{L})$.

\section{The designed extruder machine}

\subsection{Working principle and 3D model}

The aim was to build a machine that could serve as a part of a recycling line that could be used for demonstration in the laboratory. The recycling line consists of a plastic shredder, an extruder, a granulate making machine and an injection molding machine. The design of the extruder is very similar to extruders used in the industry. The working principle of the designed extruder is as follows: 1) the extruder is fed through the hopper with the shredded plastic or the granulate, after which 2) the screw, in our case a wood drill bit, transports the plastic material into the barrel by the rotating motion, 3) due to the heating system the thermoplastic material melts and is forced out on a die, generating a filament with $3 \mathrm{~mm}$ diameter cross section. The die also contain a valve that can be used to increase the pressure in the barrel, thus increasing the homogenization of the melt, 4) the turning motion of the screw, the wood drill, is ensured by an AC motor, that is connected to the wood drill with a special connector through the reducer.

\subsection{Components}

\subsubsection{Screw}

One of the most important components of the extruder is the screw. The regular extruder screw has 3 different zones: feeding, compression and homogenization zones. The inner diameter of the screw increases in the compression zone, thus reducing the space where the molten polymer material is located, resulting in the increase of the pressure. These screws are very expensive and keeping a cost-effective approach we have used a wood drill instead (Figure 2.). The diameter of the wood drill is $26 \mathrm{~mm}$, length is 600 and the active length is $530 \mathrm{~mm}$. The end of the drill has a hexagonal cross section.

\subsubsection{Barrel}

The extruder barrels used in the plastic industry are rather complicated and expensive. The extruder barrel contains cooling lines in the proximity of the feed throat to avoid melting of the granulate in the hopper. If the plastic granulates melts at the feeding section it could form a granulate aggregate that could clog the hopper, thus preventing the granulate from reaching the extruder barrel and screw.

Figure 3. shows the barrel of the designed extruder, that is a piece of a metal tube with $30 \mathrm{~mm}$ outer diameter and $26 \mathrm{~mm}$ inner diameter. This tube was selected based on the outer diameter

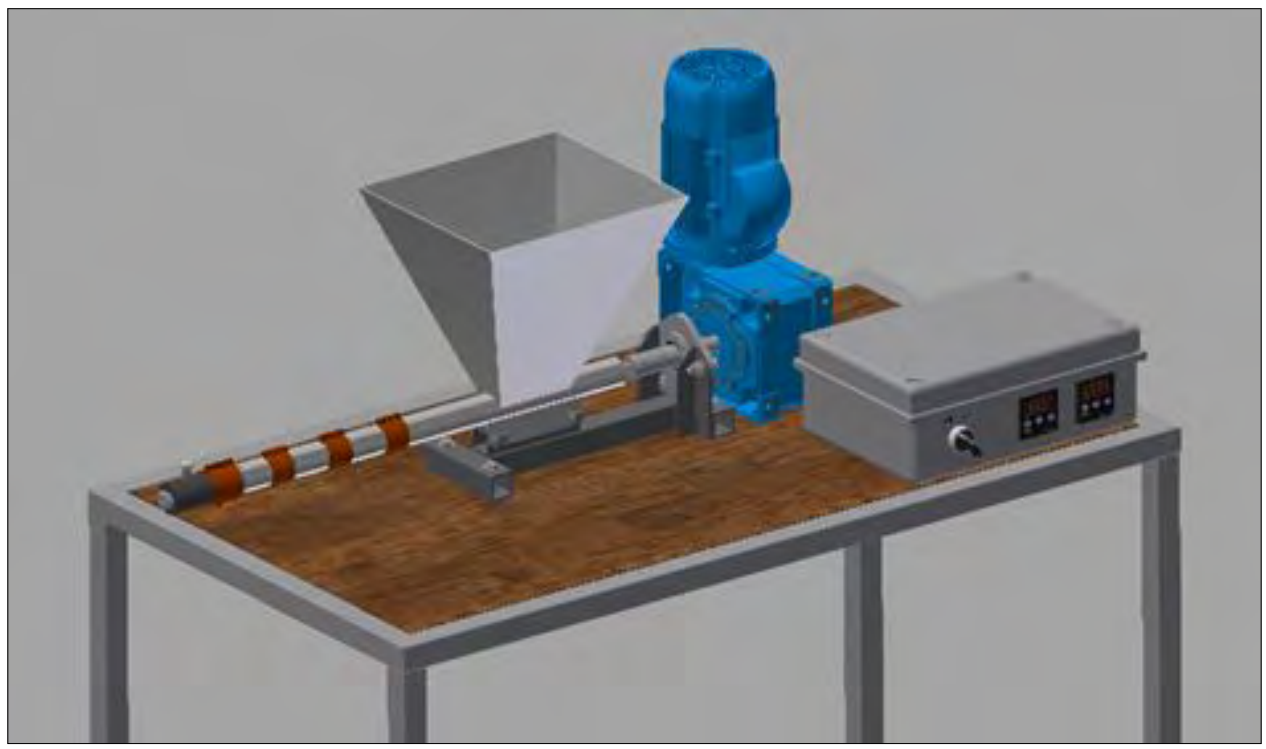

Figure 1.3D model of the designed extrude machine. 
of the wood drill. It is essential that the distance between the outer diameter of the wood drill and the inner diameter of the tube is between $0.002-0.005^{*} \mathrm{D}$, where $\mathrm{D}$ is the diameter of the screw (wood drill). The outer diameter of the tube is determined by the size of the available ring type heating units and so as to withstand the pressure that builds up during the extrusion process. One end of the barrel has a fine pitched M30 tread on the outer surface in order to connect with the die through a connector piece, whereas the feeding throat is designed to the other end of the tube as seen in Figure 3.

\subsubsection{Connector piece and the die}

Figure 4. shows the connector piece and the die. We aimed to design an instrument that can be easily assembled and transported to a different location if needed. The die is connected to the barrel via a connector. The connector piece also contains a manual valve that can be used to generate backpressure in the barrel. The die in our case is an M12 screw that contains a $3 \mathrm{~mm}$ diameter hole, thus producing a plastic filament with $3 \mathrm{~mm}$ diameter. If the size or the shape of the die should change, the new die can be screwed in to the connector in place of the old one. The connector piece is connected to the barrel via an M30 fine pitched thread. The connector contains a hole with $6 \mathrm{~mm}$ in diameter in order for the melt to be able to pass through it. The manual valve is an M8 screw that is positioned perpendicular to the $6 \mathrm{~mm}$ hole that passes through the connector piece. The connector piece also contains the place where the thermometer is connected via an M6 thread. Two milled pockets are located on the connector piece in order to help to tighten the connector piece to the barrel with a $30 \mathrm{~mm}$ wrench and to the diet.

\subsubsection{Heating}

Figure 5. show the heating unit. The barrel of the extruder is heated by four heating units, each has a power of $200 \mathrm{~W}$, and a diameter of $35 \mathrm{~mm}$. The temperature control is achieved by a PIC controller (PID REX-C100), to which the input signal is generated by two thermocouples (2M K type).

The four heating units are connected to the two temperature controllers through relays (SSR4028ZA2) that allow the supply of the heating unit with $230 \mathrm{~V}$, since the output from the controller is $5 \mathrm{~V}$.

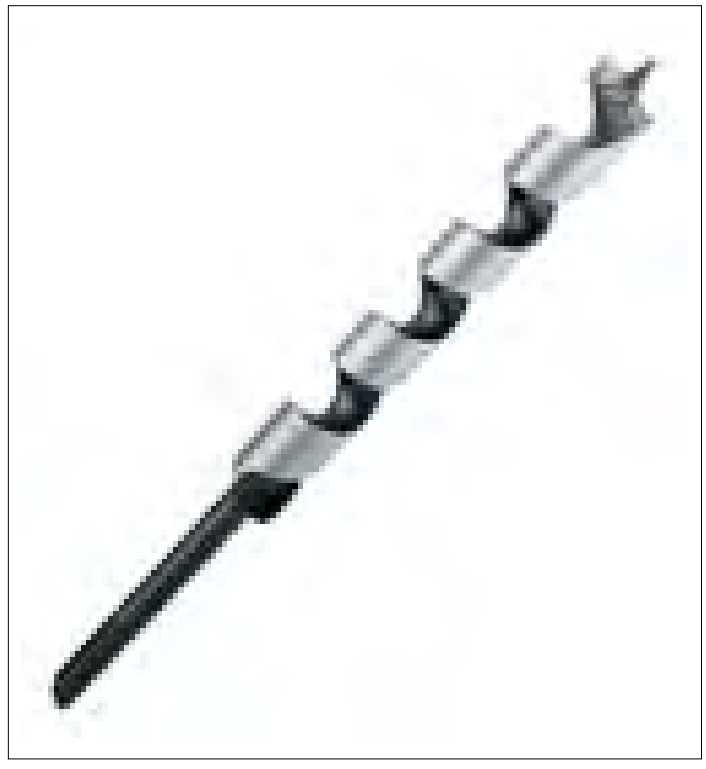

Figure 2. Wood drill serving as the screw of the extruder [5]

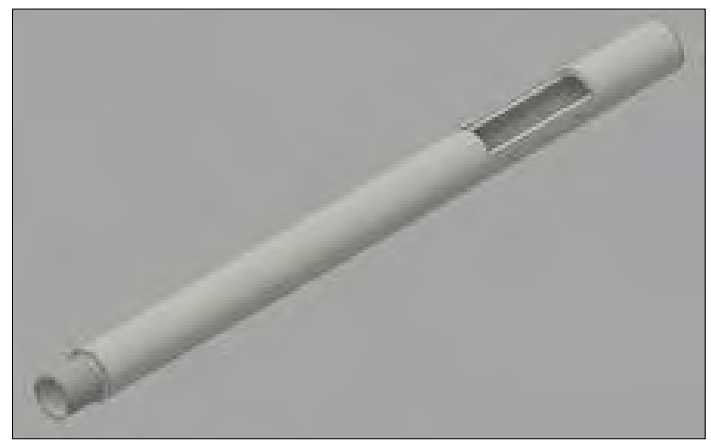

Figure 3. Barrel

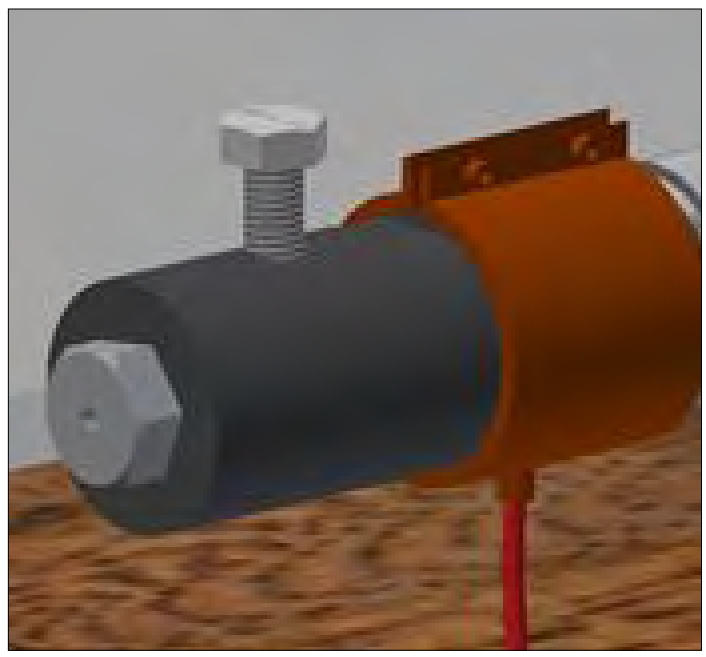

Figure 4. The die and the connector piece 


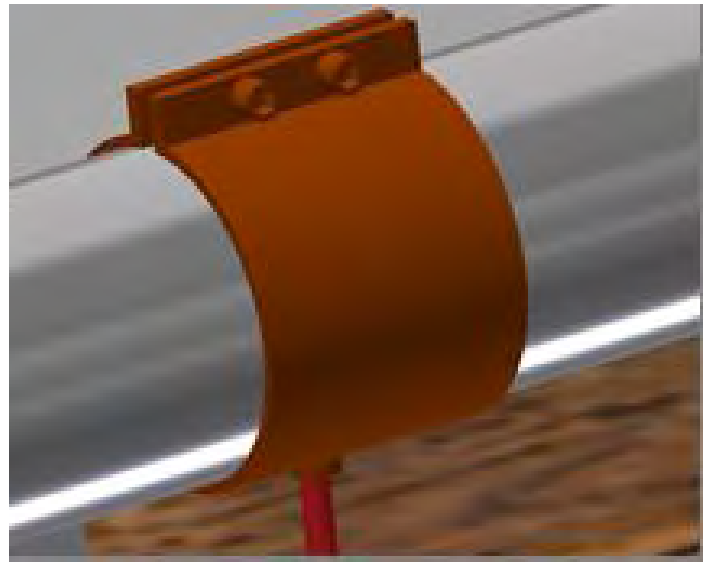

Figure 5. Heating unit

\subsubsection{Electric motor}

The drill is driven by a $0.75 \mathrm{~kW}$ AC single phase motor that also equipped with a speed reducer. The nominal speed of motor is 1400 RPM, however with the reducer ration of $\mathrm{i}=20$ the screw rotates with $70 \mathrm{RPM}$ producing $82 \mathrm{Nm}$ torque.

\section{Conclusions}

The paper presents the design steps and com-ponents of a polymer extrusion machine, that is designed following a cost-effective approach. The instrument will be set up and used in the Polymer processing laboratory at the Sapientia University to demonstrate the extrusion process of thermoplastics to students. Compared to the designs that are available in the industry we have replaced the screw with a wood drill, the barrel with metal pipe and the die with a M12 screw, which has an opening on it.

In the process of designing the machine, as a student, I have met and solved several problems. I have implemented my knowledge in 3D modelling, that clarified several design flaws in the instrument.

\section{References}

[1] John W., sons., Principles of Polymer Processing. Tadmor and Gogos, 2006.

[2] Czvikovszky T., Nagy P., Gaál J.: A polimertechnika alapjai. Műegyetemi kiadó, Budapest, 2000. 240-289.

[3] Rauwendaal C.: Polymer Extrusion. 4th ed., Hanser Publications, Munich, 2001. 6-8.

[4] Harold F. G., John R. W., Eldridge M. M.: Extrusion The definitive processing guide and handbook. Plastics Design Library, New York, 2004. 13-21.

[5] Forest technologie. Burghiu lemn. (accessed on: $21^{\text {th }}$ Febr. 2019)

https://www.sculeforest.ro/cumpara/burghiu\%CF\% 8614-600mm-360mm-lemn-spiralakeil-7478703 